\title{
Metastatic lung carcinoma presenting as intussusception of the ascending colon
}

\author{
D.R. Halleran ${ }^{1}$, B.E. Onderdonk ${ }^{* 2}$ \\ ${ }^{1}$ Department of Surgery, Upstate Medical University Syracuse, New York, USA \\ ${ }^{2}$ College of Medicine, Upstate Medical University Syracuse, New York, USA
}

Received: September 5, 2015

DOI: $10.5430 /$ crcp.v4n1p52
Accepted: November 8, $2015 \quad$ Online Published: November 29, 2016

URL: http://dx.doi.org/10.5430/crcp.v4n1p52

\begin{abstract}
Introduction: Lung cancer remains a leading cause of cancer deaths worldwide, and an estimated 50\% of cases are associated with metastasis at the time of diagnosis. We present the case of a 45-year-old female smoker with a history of right upper lobectomy with radiation for lung adenocarcinoma who, nine months later, presented with abdominal pain and was found to have an isolated metastatic lesion to the cecum causing intussusception.

Case description: A 45-year-old woman presented with a two-day history of abdominal pain, melena, fever, and chills. A diagnostic workup revealed a mass in the cecum and a colocolic intussusception. The patient underwent right hemicolectomy and was discharged following a slow recovery. Microscopic examination of the lesion revealed an adenocarcinoma histologically identical to the primary lung tumor. Further workup failed to uncover any further evidence of disease. The patient continues to be well after 23 years of clinical follow-up.

Discussion: Metastasis to the colon is a rare event but represents advanced disease and the prognosis is poor. Symptomatic involvement of the colon has only been reported in fourteen previous cases.

Conclusions: Although uncommon, metastatic disease from lung to colon should be considered in patients with lung and large bowel masses diagnosed within a relatively short time course. More likely are synchronous primaries or colon metastasis to the lung, but an accurate diagnosis is critical. Lung metastasis to the bowel portends a poor prognosis, but isolated metastatic disease can be surgically resected for cure as demonstrated in our case.
\end{abstract}

Key Words: Lung adenocarcinoma, Colocolic intussusception, Colon, Cecum, Metastasis, Non-small cell lung cancer, Cancer

\section{INTRODUCTION}

Lung cancer is a leading cause of cancer deaths worldwide, accounting for $18 \%$ of cancer deaths in $2008 .{ }^{[1]}$ Metastatic disease is common and portends a poor prognosis for patients. Colonic metastasis of primary lung cancers are a rare event and represent advanced disease. Herein we present the case of a 45-year-old woman with a history of resected lung adenocarcinoma who presented with intussusception of the ascending colon and found to have metastatic disease that was successfully resected and is well after 23 years.

\section{CASE DeSCRIPTION}

A 45-year-old woman presented to the emergency department with a two-day history of abdominal pain, melena, fever, and chills. Nine months earlier she underwent right upper lobectomy with resection of multiple ribs with postoperative external beam radiation therapy for a $3.5 \mathrm{~cm}$ T3 N0

\footnotetext{
* Correspondence: B.E. Onderdonk; Email: benonderdonk@gmail.com; Address: College of Medicine, Upstate Medical University Syracuse, New York, USA.
} 
M0, stage IIB, poorly-differentiated adenocarcinoma of the lung (see Figure $1 \mathrm{~A}, \mathrm{~B}$ ). The tumor was found to involve the chest wall but not the bronchial or mediastinal lymph nodes.
Further workup at that time, including CT scan of the brain and thorax, bone scan, bronchoscopy, and mediastinoscopy revealed no evidence of disseminated disease.

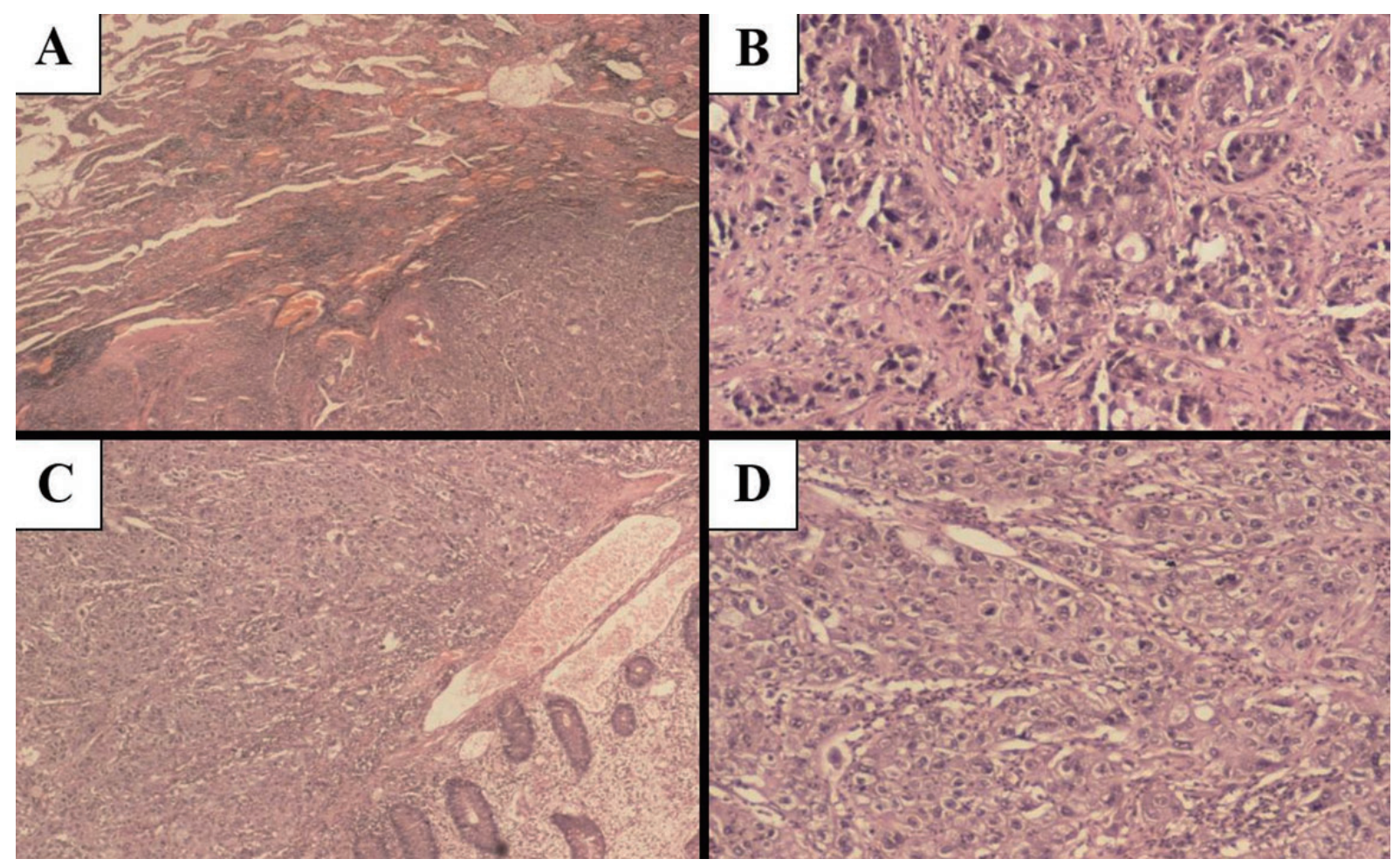

Figure 1. Histopathologic demonstration of the primary and metastatic lesions

(A) Low-power magnification $(\times 100)$ of the poorly differentiated primary adenocarcinoma in the lung. $(B)$ High-power magnification $(\times 400)$ of the primary lung lesion demonstrates atypical cells with a high nuclear-to-cytoplasmic ratio. $(C)$ The intestinal lesion at low-power magnification $(\times 100)$ is histologically identical to the primary lung adenocarcinoma. The carcinoma can be seen on the left with the normal appearing intestinal mucosa on the right. The serosa is not depicted in the photograph. (D) High-power magnification $(\times 400)$ of the metastatic cecal lesion.

Physical examination at the time of presentation revealed clear lung sounds bilaterally. Her abdominal examination demonstrated right lower quadrant and mid-epigastric tenderness to palpation without masses, guarding, or rebound. Digital rectal examination was guaiac positive. The patient's hematocrit on admission was 29 . An upper endoscopy was negative. Subsequent $\mathrm{CT}$ revealed a large, $8 \mathrm{~cm}$. mass in the ascending colon (see Figure 2A). Gastrografin enema revealed an intussuscepting mass in the right colon (see Figure 2B). She underwent right hemicolectomy (see Figures 3-4). Her post-operative course was slow and complicated by prolonged ileus and pyelonephritis. She was discharged on post-operative day \#19.

Microscopic examination of the surgical specimen showed a poorly differentiated adenocarcinoma in the cecum mostly confined to the wall but focally penetrating to the serosa (see Figure 1C). The specimen was histologically identical to the primary lung mass (see Figure 1D). Resection margins and all 20 mesenteric lymph nodes were negative for disease. She received no adjuvant chemotherapy or radiation following the abdominal surgery. Follow-up failed to find any recurrence of disease and she continues to be well and follow in our clinic, 23 years later.

\section{DISCUSSION}

At the time of diagnosis, approximately one-half of lung carcinomas are associated with metastasis. ${ }^{[2]}$ Common sites of metastasis include brain, bone, adrenal glands, and liver. ${ }^{[3]}$ Distant metastasis portend a poor prognosis for patients, and the 5-year mean life expectancy for non-small cell lung cancer is $18 \% .{ }^{[4]}$ The gastrointestinal tract is relatively rare site for metastasis from primary lung tumors, and of those cases the colon is only involved in $0.2 \%-0.5 \%$ of cases. ${ }^{[5,6]}$ There exist very few case reports of symptomatic colonic involvement of primary lung lesions. A recent review identified only 14 such cases in the English literature. ${ }^{[7,12]}$ Abdominal pain 
and anemia were common presenting symptoms, with ob- months from the time of diagnosis. ${ }^{[7]}$ Survival ranged from struction, lower GI bleeding, bowel perforation, or GI fistula 5 weeks to 1 year, with few extending beyond 6 months. also reported. Symptoms have been reported as late as 32

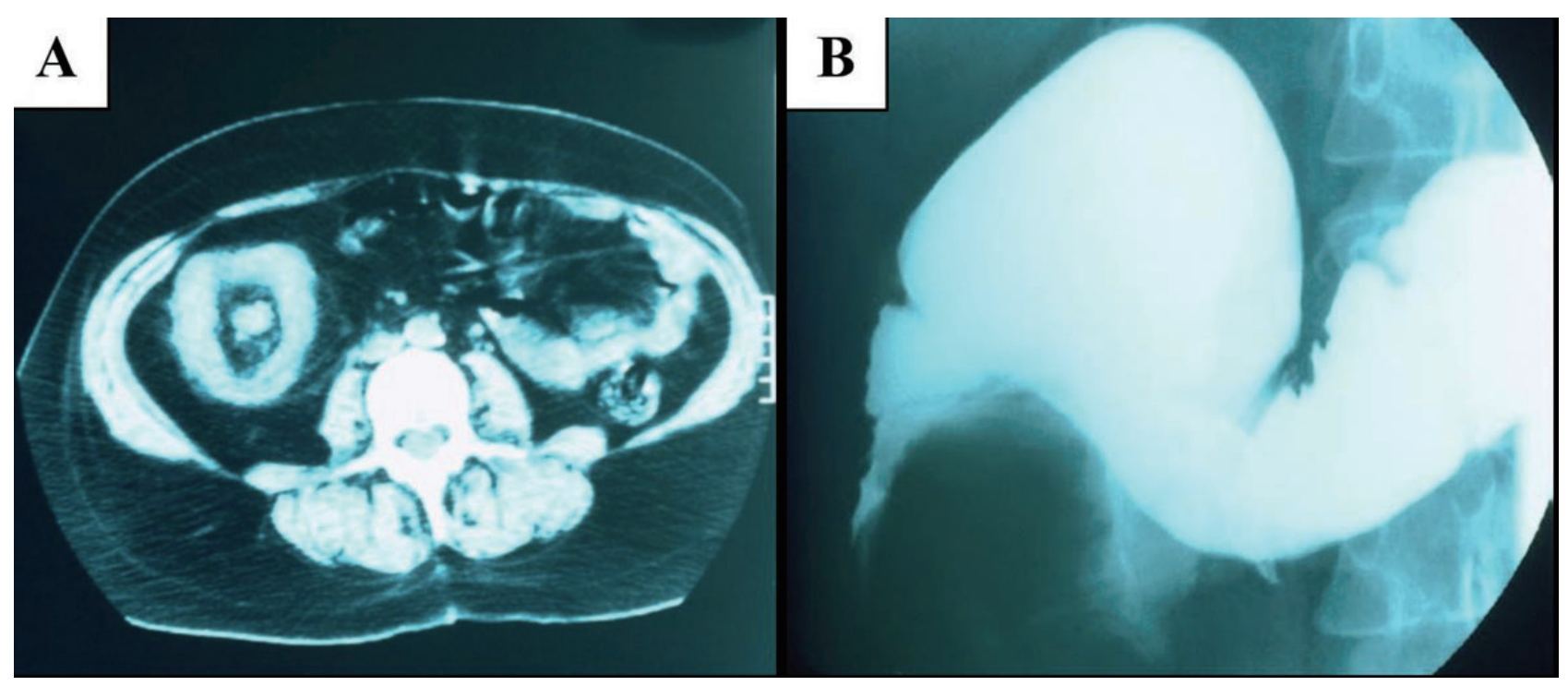

Figure 2. Imaging studies obtained at the time of presentation (A) CT demonstrates the intussuscepting ascending colon resulting in the radiographic target sign. (B) Barium enema showing the colocolic intussusception. It is possible to see the intussusceptum (inferior) and the intussuscipiens (superior).

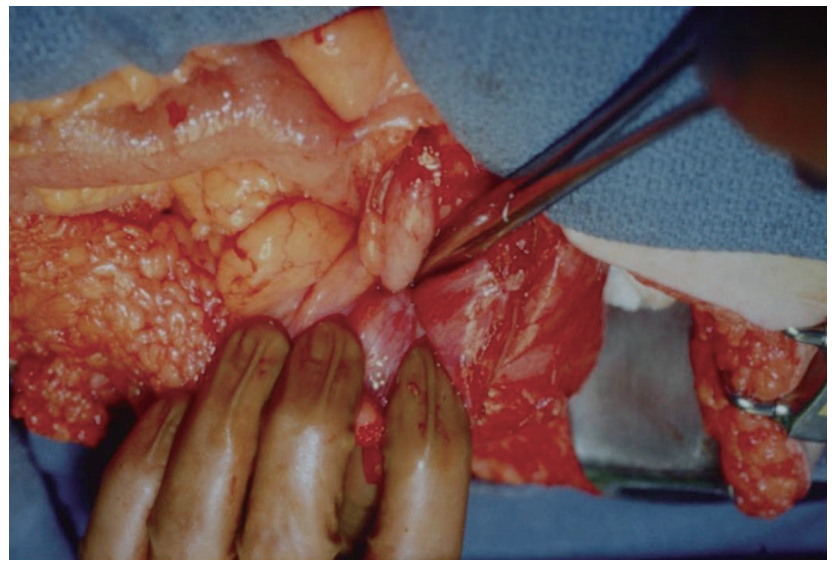

Figure 3. Intraoperative image of the colocolic intussusception. The ilium is pictured on the right.

Distinguishing between metastatic lung disease to the colon and a primary colon adenocarcinoma is necessary as the management is specific for each. Immunohistochemical markers can reliably differentiate between primary lesions at both sites, as lung adenocarcinomas express thyroid transcription factor-1 (TTF-1) and cytokeratin 7 (CK7) but not cytokeratin 20 (CK20) or CDX-2, whereas primary colon adenocarcinomas express CK20 and CDX-2 but not TTF- 1 or CK7. ${ }^{[8]}$ One study demonstrates that a combination of TTF-1+, CK7+, CK20- is highly specific for lung adenocarcinoma $(p<.001)$, and TTF-1-, CK7-, CK20+ is extremely specific for gastrointestinal adenocarcinoma $(p<.001) .{ }^{[9]}$ This case occurred prior to the development of these markers. However, features that lead to a conclusion of a metastatic lung tumor to the cecum rather than the more common a colorectal lesion metastatic to the lung or synchronous lung and colon lesions include the absence of mucosal involvement of the lesion, which is common in primary colorectal lesions. Furthermore, the features favoring a metastatic lesion from the lung primary include the clear cell component and only focal mucin production in the tumor specimen. Lastly, metastatic workup at the time of the initial diagnosis failed to show any cecal involvement.

This report is the first known case of colonic intussusception as the presenting sign of colonic metastasis of a primary lung adenocarcinoma. Intussusception occurs when a portion of bowel invaginates an adjacent segment, often leading to obstructive symptoms including nausea, vomiting, and abdominal pain. Common too is melena, fever, constipation, and diarrhea. Often considered a pediatric condition, intussusception in adults is a rare event and often associated with malignancy. In contrast to pediatric cases, the initial management of adult intussusception is surgical and must be followed by a cancer workup as up to $50 \%$ of cases are caused by a malignant lesion serving as a lead point for the telescoping bowel. ${ }^{[10]}$ 

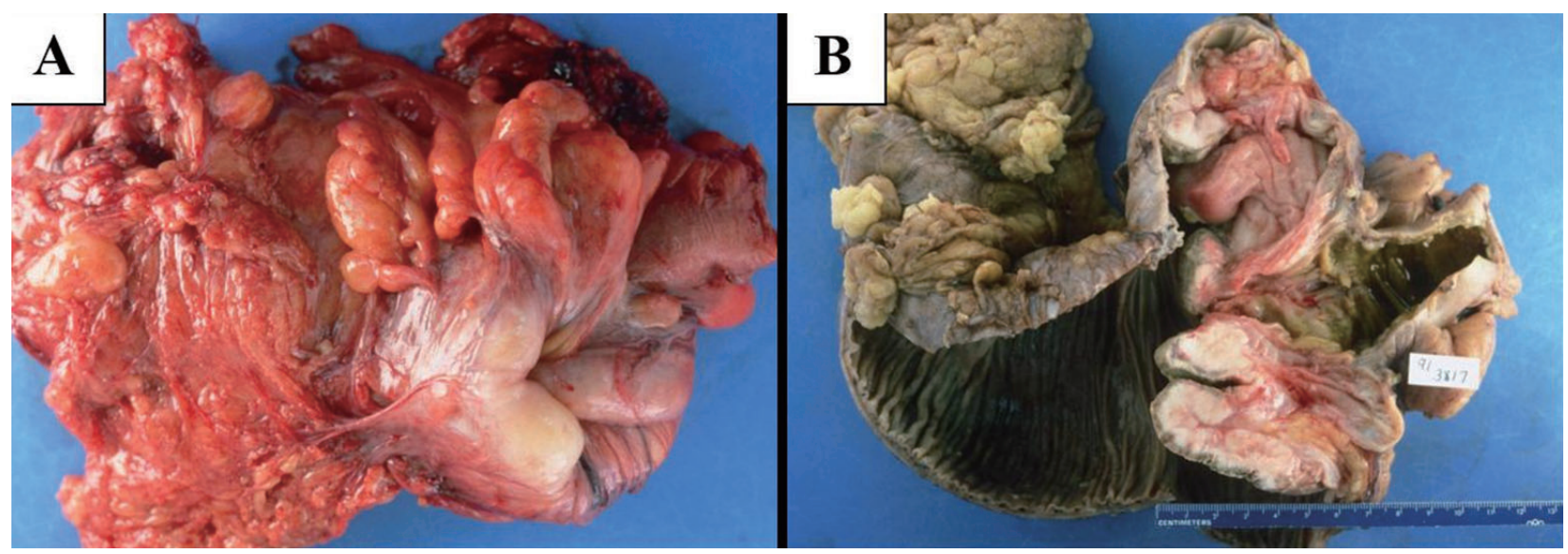

Figure 4. (A) Gross surgical specimen before fixation. (B) Examination of the specimen after fixation demonstrates a fungating, polypoid, circumferential mass measuring $6 \mathrm{~cm} \times 9 \mathrm{~cm} \times 6 \mathrm{~cm}$ in the cecum.

\section{Conclusions}

This represents the first case of a definitive surgical cure for a symptomatic colonic metastasis. It is important for the clinician to consider GI metastasis in patients with newly diagnosed lung carcinoma and sudden onset GI symptoms because of the morbidity and mortality associated with symptomatic GI involvement. While surgical treatment of lung cancer metastatic to the GI tract is generally reserved for palliation, ${ }^{[11]}$ our case demonstrates the possibility of a curative surgical resection for isolated distant metastatic disease from primary lung tumors.

\section{CONFlicts of InTERest Disclosure}

The authors have no financial conflicts of interest to declare.

\section{REFERENCES}

[1] Jemal A, Bray F, Center MM, et al. Global Cancer Statistics. CA Cancer J Clin. 2011; 61: 69-90. PMid: 21296855. https://doi. org/10.3322/caac. 20107

[2] Yang CJ, Hwang JJ, Kang WY, et al. Gastro-intestinal metastasis of primary lung carcinoma: clinical presentations and outcome. Lung Cancer. 2006; 54(3): 319-23. PMid: 17010474. https: //doi.org/10.1016/j.lungcan.2006.08.007

[3] Quint LE, Tummala S, Brisson L, et al. Distribution of distant metastases from newly diagnosed non-small cell lung cancer. Ann Thorac Surg. 1996; 62: 246-50. https://doi.org/10.1016/0003-497 5 (96) 00220-2

[4] American Cancer Society. Cancer Facts \& Figures 2014. Atlanta: American Cancer Society; 2014.

[5] Kim MS, Kook EH, Ahn SH, et al. Gastrointestinal metastasis of lung cancer with special emphasis on a long-term survivor after operation. J Cancer Res Clin Oncol. 2009; 135: 297-301. PMid: 18512073. https://doi.org/10.1007/s00432-008-0424-0

[6] Berger A, Cellier C, Daniel C, et al. Small bowel metastases from primary carcinoma of the lung: clinical findings and outcome. Am J Gastroenterol. 1999; 94: 1884-7. PMid: 10406253. https://doi.org/10.1111/j.1572-0241.1999.01224.x
[7] Lou HZ, Wang CH, Pan HM, et al. Colonic metastasis after resection of primary squamous cell carcinoma of the lung: A case report and literature review. World J Gastroenterol. 2014; 20(19): 5930-4. PMid: 24914356. https://doi.org/10.3748/wjg.v20.i19.5930

[8] Yousem SA. Pulmonary intestinal-type adenocarcinoma does not show enteric differentiation by immunohistochemical study. Mod Pathol. 2005; 18: 816-21. PMid: 15605076. https ://doi .org/10 $.1038 /$ modpathol .3800358

[9] Su YC, Hsu YC, Chai CY, et al. Role of TTF-1, CK20, and CK7 immunohistochemistry for diagnosis of primary and secondary lung adenocarcinoma. Koahsiung J Med. Sci. 2006; 22(1): 14-9.

[10] Azar T, Berger DL. Adult intussusception. Annals of Surgery. 1997; 226(2): 134-8. PMid: 9296505. https://doi.org/10.1097/00 000658-199708000-00003

[11] Goh BK, Yeo AWY, Koong HN, et al. Laparotomy for acute complications of gastrointestinal metastases from lung cancer: is it a worthwhile or futile effort? Surg Today. 2007; 37: 370-4. PMid: 17468816. https://doi .org/10.1007/s00595-006-3419-y

[12] Chen J. Undiagnosed primary lung carcinoma with initial manifestation of intestinal obstruction: A case report and literature review. J Can Res Ther. 2015; 11: 134-7. PMid: 26323914. https: //doi.org/10.4103/0973-1482.163873 